\title{
An Updated Analysis of Direct-to-Consumer Television Advertisements for Prescription Drugs
}

\author{
Janelle Applequist, $P b D^{1}$ \\ Jennifer Gerard Ball, $P b D^{2}$ \\ 'Zimmerman School of Advertising and \\ Mass Communications, University of South \\ Florida, Tampa, Florida \\ ${ }^{2}$ Klein College of Media and Communi- \\ cation, Temple University, Philadelphia, \\ Pennsylvania
}

Conflicts of interest: authors report none.

\footnotetext{
CORRESPONDING AUTHOR

Janelle Applequist, $\mathrm{PhD}$

Zimmerman School of Advertising and Mass Communications

University of South Florida

4202 E Fowler Avenue, CIS 1040

Tampa, FL 33620

applequist@usf.edu
}

\begin{abstract}
PURPOSE In 2015, the American Medical Association called for a ban of directto-consumer advertising (DTCA) for prescription drugs. Yet, the pharmaceutical industry spends more than ever on broadcast advertisements, with national health care costs largely driven by drug spending. An evaluation of these ads is critical, as these advertisements can impact the frequency which patients ask their doctors about medications.
\end{abstract}

METHODS A content analysis of prime-time direct-to-consumer ads was conducted across 4 major cable television networks. The ad content $(n=61)$ was coded for factual claims made regarding target conditions, appeals used, portrayal of medications, and lifestyle characteristics shown.

RESULTS We found a substantial decrease in the percentage of ads that conveyed information about the conditions being targeted, such as risk factors (16\%) and prevalence (16\%). Positive emotional appeals (94\%) continued to be emphasized; yet there was decreased use of negative emotional appeals (51\%), pointing to an overall more positive portrayal of a patient's experience with a medication. The lifestyles portrayed in the sample largely featured how products can enable more recreational activities (69\%) and fewer ads (7\%) presented alternatives to product use.

CONCLUSIONS Direct-to-consumer advertising continued to promote prescription drugs above educating the population. Improvement in the educational value of DTCA is likely to require regulatory action rather than reliance on self-regulation by the pharmaceutical industry.

Ann Fam Med 2018;16:211-216. https://doi.org/10.1370/afm.2220.

\section{INTRODUCTION}

$\mathrm{T}$ wenty years ago, the US Food and Drug Administration (FDA) relaxed the risk information disclosure requirements for direct-toconsumer advertisements (DTCA) of prescription drugs appearing on television or radio. Since that time, DTCA has become a mainstay of consumer broadcast media. Total expenditures on DTCA topped 6 billion dollars in recent years with television commercials accounting for the majority of expenditures. ${ }^{1}$ Accordingly, most Americans are aware of DTCA, and a substantial minority (18\% to $30 \%$ ) claim to have visited a doctor after seeing a drug ad. ${ }^{2-4}$

Despite the ubiquity of DTCA, debate surrounding it lingers. Proponents generally tout the information in the ads as educational and motivating while critics regard the information as biased and misleading. A prior study of direct-to-consumer television commercials suggested DTCA may motivate doctor visits but falls short of its educational promise. ${ }^{5}$ Specifically, the study found the ads were better at providing basic information about symptoms than explanations of the mechanism, risk factors, or prevalence of the condition. The ads tended to downplay negative lifestyle changes, prominently utilized emotional appeals, and promised broad effects of medication use such as patients regaining control over their lives. The original study generated extensive commentary, both supportive 
and critical of DTCA, and has continued to serve as a key reference for researchers, policy makers, and other stakeholders. $^{6}$

It is important to note that the advertisements analyzed previously aired in the first half of $2004,{ }^{5}$ and since that time, there have been several important developments in the DTCA landscape. The pharmaceutical industry experienced high-profile controversies including the recall of Vioxx in 2004 and the revelation that ads falsely depicted the Lipitor spokesperson, Dr Jarvik, as a licensed physician. The Institute of Medicine called for a 2-year moratorium on DTCA for newly approved drugs in 2007, and the American Medical Association voted in favor of a ban on DTCA in 2015,7,8

Policy makers have rejected or ignored proposals to ban DTCA, but regulation has evolved. The FDA Amendments Act of 2007 required drug makers to submit television advertisements 45 days before the first airing. ${ }^{9}$ The FDA has drafted updated guidance to standardize the appearance of drug brand names, to clarify points regarding the fair and balanced presentation of benefit and risk information, and to specify regulatory guidelines to be applied to online advertisements. ${ }^{10}$

In response to certain pressures and challenges, the Pharmaceutical Researchers and Manufacturers of America (PhRMA) issued 2 iterations of self-regulatory principles. The initial set of principles, presented in 2005, stated that information about drug benefits and risks should be accurate, clear, balanced, and evidencebased in compliance with regulations. ${ }^{11}$ In addition, several principles called for ads to responsibly educate the consumer about the medicine and the condition, promote health and disease awareness, and inform the audience about other options such as diet and lifestyle changes where appropriate. ${ }^{12}$ In 2008, the guidelines were updated to denounce the promotion of off-label medication uses and benefits, to compel clear identification of actor and celebrity endorsers, and to reiterate the revised FDA guidance that risk and benefit information were to be presented with equivalent prominence using clear, conspicuous, and neutral language. ${ }^{12}$

It is reasonable to expect the aforementioned changes and events may have influenced the content of DTCA, but there has been a paucity of research evaluating the content of broadcast DTCA since these changes went into effect. The few studies conducted in the interim have been too narrowly focused to gauge changes or improvements in the design of DTCA. It is crucial to have an up-to-date content analysis examining the message strategies employed by pharmaceutical advertisers to ensure that ongoing research and debate regarding DTCA is reflective of current ad practices.
To that end, we analyzed direct-to-consumer television ads using the prior study ${ }^{5}$ as a model and benchmark.

\section{METHODS}

\section{Sampling Strategy}

We examined ads appearing on 4 major US television networks (ABC, CBS, NBC, and FOX) for a 13-week period (July 17 through October 18, 2016). SnapStream was used to record all ads airing during primetime television hours (8:00-11:00 PM EST MondaySaturday and 7:00-11:00 PM EST Sunday). The lead researcher viewed all content and searched accompanying transcripts to identify DTCA in the sample.

The FDA identifies 3 types of prescription drug ads (product claim, reminder, and help-seeking). Product claim ads, the type that consumers are most familiar with, provide the name of a drug, the condition it treats, and discuss its benefits and risks. ${ }^{13}$ Reminder ads reveal a drug's name but not its uses, and do not contain risk information, what the drug is, or how it works. ${ }^{13}$ Reminder ads were not present in this sample set and currently are rarely used in DTCA. Helpseeking ads, which describe a disease or medical condition but do not recommend a specific drug, appeared in our sample but were not analyzed due to their limited presence. This study only evaluated product claim ads. Product claim ads comprise the vast majority of DTCA and have the greatest implications for policy and practice because they contain the most comprehensive information. ${ }^{14}$

\section{Ad Coding}

We adopted the published coding scheme ${ }^{5}$ to allow a direct comparison (Table 1) as the coding categories have been replicated and used in previous research. ${ }^{14}$ Ads were coded for factual claims presented about the indicated health condition, including (1) any factual information provided, (2) biologic nature or mechanism, (3) risk factors or cause, (4) prevalence, and (5) the subpopulation at risk. Types of appeals coded were (1) rational-use of informational or logical arguments to present the product, its use, or features of the drug (2) positive emotional-depiction of favorable emotions or affect (eg, showing characters as joyful) $)_{i}(3)$ negative emotional-portrayal of negative emotions such as disgust, fear, or anger ${ }_{i}$ (4) humor-use of puns, jokes, or satire ${ }_{i}(5)$ fantasy-depiction of surreal or unrealistic scenes; (6) sex-portrayal of an intimate encounter between characters or provocative situations; and (7) nostalgic-appealing to tradition, heritage, or the past through the use of black-and-white or sepia-toned visuals, or images from an earlier time. In addition, codes for thematic concepts (eg physical activity) 
were applied to identify how the ads portrayed the indicated health condition and the role of medication in the lives of patients.

Two graduate-level research assistants were trained as coders for a total of 36 hours over the course of 1 year using a separate collection of DTCA not included in the main sample. Both coders then independently coded all ads in the main sample to establish intercoder reliability.

\section{Coding Reliability and Frequency Presentation} Intercoder reliability, calculated using $\kappa$, showed high levels for all coding categories ranging from 0.81 to 1.00. Remaining discrepancies between coders were resolved through discussion and further training. The analysis was based on weighted frequencies calculated by multiplying the frequency of coded elements for each ad by the total number of times that ad appeared in the sample $(M=14.2, \mathrm{SD}=12.4$, range $=1-58)$ to facilitate comparison of our results to a prior study. ${ }^{5}$

\section{RESULTS}

Direct-to-consumer product claim ads aired 868 times during the collection period. After removing duplicates, the sample had 61 unique product claim ads for 35 prescription drug brands. The results of our study are referred to as the "2016 sample" (Table 1). The results reported previously ${ }^{5}$ are referenced for comparison and designated as the "2004 sample". Table 2 lists the drug brands, manufacturers, and indicated health conditions in the 2016 sample. Similar descriptive information from the 2004 sample is featured in Table 3 for comparison.

\section{Ad Length and Story Structure}

The average ad length in the 2016 sample was longer $(M=67.4$ seconds, $\mathrm{SD}=17.3$, range 30-120), than the average ad length $(M=51.8$ seconds) in the 2004 sample. Nearly one-half of the 2016 ads (41.0\%) featured human characters before and after taking the product. A greater proportion of ads in 2016 (56.9\%) showed characters only after taking the product, a substantial increase from the $39.5 \%$ of ads featuring only post-medication depictions in the 2004 sample. The remaining 2016 ads $(2.1 \%)$ did not use human characters or did not clearly indicate if a main character had taken the product.

\section{Factual Claims About the Target Condition}

Similar to the 2004 sample, many of the 2016 ads featured facts related to the indicated health condition. Fewer of the 2016 ads, however, provided information related to the biologic nature, risk factors or causes, or prevalence of the condition compared with the 2004 sample. We also noted that none of the 2016 ads provided quantitative estimates of the condition prevalence (eg, 1 in 4), but instead provided qualitative descriptions such as thousands or many. Factual information about the indicated health condition was stated at the beginning of the advertisement.

\section{Appeals}

The frequency of rational and positive emotional appeals used in 2016 ads remained high, consistent with the 2004 sample, but there was a decrease in the use of negative appeals. Positive emotional appeals were most frequently portrayed in the context of

\begin{tabular}{|c|c|c|}
\hline Content Category & $\begin{array}{l}2004 \text { Sample } \\
\quad(n=31)\end{array}$ & $\begin{array}{l}2016 \text { Sample } \\
\quad(n=61)\end{array}$ \\
\hline \multicolumn{3}{|l|}{ Factual claims } \\
\hline Any factual information (eg, symptoms) & 82.0 & 77.4 \\
\hline Biologic nature or mechanism of disease & 53.9 & 24.5 \\
\hline Risk factors or cause of condition & 25.8 & 16.3 \\
\hline Prevalence of condition & 24.7 & 15.8 \\
\hline Subpopulation at risk of condition & 7.9 & 9.1 \\
\hline \multicolumn{3}{|l|}{ Appeals } \\
\hline Rational & 100.0 & 100.0 \\
\hline Positive emotional & 94.4 & 94.1 \\
\hline Negative emotional & 75.3 & 50.8 \\
\hline Humor & 36.0 & 8.9 \\
\hline Fantasy & 22.5 & 13.7 \\
\hline Sex & 4.5 & 6.2 \\
\hline Nostalgia & 3.4 & 11.1 \\
\hline \multicolumn{3}{|l|}{ Lifestyle portrayals } \\
\hline $\begin{array}{l}\text { Condition interferes with healthy or } \\
\text { recreational activities }\end{array}$ & 30.3 & 47.5 \\
\hline $\begin{array}{l}\text { Product enables healthy or recreational } \\
\text { activities }\end{array}$ & 56.2 & 68.8 \\
\hline Lifestyle change is alternative to product use & 0.0 & 0.0 \\
\hline Lifestyle change is insufficient & 21.3 & 19.9 \\
\hline Lifestyle change is adjunct to product & 22.5 & 7.4 \\
\hline \multicolumn{3}{|l|}{ Medication portrayals } \\
\hline Loss of control caused by condition & 67.4 & 59.7 \\
\hline Regaining control as result of product use & 88.8 & 95.7 \\
\hline Social approval as a result of product use & 83.1 & 90.8 \\
\hline Distress caused by condition & 53.9 & 58.9 \\
\hline Breakthrough & 67.4 & 69.5 \\
\hline Endurance increased as a result of product & 12.4 & 23.5 \\
\hline Protection as a result of product use & 11.2 & 24.5 \\
\hline
\end{tabular}


a character's happy mood after taking the product, whereas negative emotions were evoked when portraying a patient's experience with their condition before the medication was prescribed.

\section{Lifestyle Portrayals}

The 2016 ads had increased portrayals of medical conditions interfering with healthy or recreational activities and of the product enabling healthy or recreational activities. Physical activity was featured in $58 \%$ of the 2016 ads, with characters shown engaging in moderate or vigorous physical activity, such as bicycling, hiking, running, or playing sports (results not shown). As was the case with the 2004 sample, many of the 2016 ads targeted conditions that have treatment options involving some behavioral change (eg, diabetes, fibromyalgia, submental fullness). Yet, none of the ads offered behavioral change as an alternative to taking medication and fewer ads in the 2016 sample presented the drug as a beneficial addition to lifestyle changes such as diet and exercise. The proportion of ads presenting lifestyle changes as insufficient for condition improvement remained virtually the same.

\section{Table 2. Drug Brands in Product Claim Advertisements in 2016 Sample}

\begin{tabular}{|c|c|c|}
\hline Brand Name & Manufacturer & Advertised Indication \\
\hline Breo & GlaxoSmithKline & Asthma \\
\hline Brilinta & AstraZeneca & Acute coronary syndrome \\
\hline Chantix & Pfizer & Smoking cessation \\
\hline Cialis $^{\mathrm{a}}$ & Eli Lilly & Erectile dysfunction, enlarged prostate \\
\hline Cosentyx & Novartis & Plaque psoriasis, psoriatic arthritis \\
\hline Eliquis & Bristol-Myers Squibb & Deep vein thrombosis, pulmonary embolism \\
\hline Enbrela $^{\mathrm{a}}$ & Amgen & Rheumatoid arthritis \\
\hline Entresto & Novartis & Chronic heart failure \\
\hline Farxiga & AstraZeneca & Type 2 diabetes \\
\hline Harvoni & Gilead Sciences & Hepatitis C \\
\hline Humira & AbbVie & $\begin{array}{l}\text { Crohn's disease, plaque psoriasis, psoriatic arthritis, } \\
\text { rheumatoid arthritis, ulcerative colitis }\end{array}$ \\
\hline Invokana & Janssen & Type 2 diabetes \\
\hline Jardiance & Boehringer Ingelheim & Type 2 diabetes \\
\hline Kybella & Allergan & Submental fullness \\
\hline Latuda & Sumitomo Dainippon & Bipolar depression \\
\hline Linzess & Allergan; Ironwood & Irritable bowel syndrome with constipation \\
\hline Lyrica & Pfizer & $\begin{array}{l}\text { Diabetic nerve pain, epilepsy, fibromyalgia, neuro- } \\
\text { pathic pain, post herpetic neuralgia }\end{array}$ \\
\hline Myrbetriq & Astellas & Overactive bladder \\
\hline Namenda XR & Allergan & Dementia with Alzheimer \\
\hline Opdivo & Bristol-Myers Squibb & $\begin{array}{l}\text { Hodgkin's lymphoma, lung cancer, melanoma, } \\
\text { metastatic melanoma across BRAF status }\end{array}$ \\
\hline Pradaxa & Boehringer Ingelheim & Deep vein thrombosis, pulmonary embolism \\
\hline Prevnar 13 & Wyeth; Pfizer & Pneumococcal pneumonia vaccine \\
\hline Symbicort & AstraZeneca & $\begin{array}{l}\text { Asthma, chronic obstructive pulmonary disease } \\
\text { (COPD) }\end{array}$ \\
\hline Taltz & Eli Lilly & Plaque psoriasis \\
\hline Toujeo & Sanofi & Type 2 diabetes \\
\hline Tresiba & Novo Nordisk & Type 1 or 2 diabetes \\
\hline Trintellix & Takeda & Major depressive disorder \\
\hline Trulicity & Eli Lilly & Type 2 diabetes \\
\hline Trumenba & Pfizer & Meningitis B vaccine \\
\hline Viagra & Pfizer & Erectile dysfunction \\
\hline Viberzi & Allergan & Irritable bowel syndrome with diarrhea \\
\hline Victoza & Novo Nordisk & Type 2 diabetes \\
\hline Xarelto & Janssen & $\begin{array}{l}\text { Acute coronary syndrome, deep vein thrombosis, } \\
\text { stent thrombosis }\end{array}$ \\
\hline Xeljanz & Pfizer & Rheumatoid arthritis \\
\hline Xiidra & Shire Pharmaceuticals & Chronic dry eye \\
\hline
\end{tabular}

\section{Medication Portrayals}

Almost all ads portrayed a character regaining control as a result of obtaining a prescription drug. All ads that portrayed a loss of control due to the condition (59.7\%) offered the drug as the solution to this negative experience. Most ads associated the medication with greater social approval, often depicted by showing more friends, family, and recreational activities after a character obtained a prescription. Many ads continued to frame the medication as being a type of scientific breakthrough, using words like "revolutionary," or phrases such as "for the first time ever," and "now you can...". The portrayal of endurance increasing as a result of medication use (eg, showing a character being able to go to work, participate in family activities, etc) nearly doubled in the 2016 sample (23.5\%) compared with the 2004 sample, indicating a further broadening of claims that the medications can help with patient's daily tasks and responsibilities.

\section{DISCUSSION}

This study revealed a shift in some aspects of DTCA execution. Problematic characteristics of prescription drug ads originally identified by Frosch et $\mathrm{al}^{5}$ seem to have become more extreme. For instance, 2016 ads conveyed a greater emphasis on 
Table 3. Drug Brands in Product Claim Advertisements in 2004 Sample

\begin{tabular}{|c|c|c|}
\hline Brand Name & Manufacturer & Advertised Indication \\
\hline Actonela & Procter \& Gamble & Osteoporosis \\
\hline Allegra ${ }^{a, b}$ & Aventis & Allergy \\
\hline Ambien ${ }^{c, d}$ & Sanofi-Synthelabo & Insomnia \\
\hline Celebrex ${ }^{c, d}$ & Pfizer & Overactive bladder \\
\hline Cialisce & Eli Lilly & Erectile dysfunction \\
\hline Crestor $^{\mathrm{a}, \mathrm{d}}$ & AstraZeneca & Hypercholesterolemia (high cholesterol) \\
\hline Detrol LA ${ }^{a, d}$ & Pfizer & Overactive bladder \\
\hline Diovan $^{a, d, f}$ & Novartis & Hypertension \\
\hline Diovan $\mathrm{HCT}^{\mathrm{d}}$ & Novartis & Hypertension \\
\hline Enbrela,e $^{a}$ & Immunex & Rheumatoid arthritis \\
\hline Fosamax ${ }^{a, d}$ & Merck & Osteoporosis \\
\hline Lamisila,d & Novartis & Onychomycosis (nail fungus) \\
\hline Levitra $^{a}$ & Bayer & Erectile dysfunction \\
\hline Lipitorc,d & Pfizer & Hypercholesterolemia (high cholesterol) \\
\hline Lotrel & Novartis & Hypertension \\
\hline Nexiuma,b & AstraZeneca & Gastresophageal reflux disease (acid reflux) \\
\hline Plavix & Bristol-Myers Squibb & Acute coronary syndrome \\
\hline Prevacid ${ }^{b, c}$ & TAP & Gastresophageal reflux disease (acid reflux) \\
\hline Procritc, & Amgen & Chemotherapy-related anemia \\
\hline Singulaira,d & Merck & Allergy \\
\hline Valtrex $x^{c, d}$ & GlaxoSmithKline & Genital herpes \\
\hline Zelnorma & Novartis & Irritable bowel syndrome with constipation \\
\hline Zocor ${ }^{\mathrm{a}, \mathrm{d}}$ & Merck & Hypercholesterolemia (high cholesterol) \\
\hline Zoloft ${ }^{\mathrm{a}, \mathrm{d}}$ & Pfizer & Depression, social anxiety disorder \\
\hline \multicolumn{3}{|c|}{$\begin{array}{l}\text { b Product switched to over-the-counter availability (prescription no longer required) since study's } \\
\text { publication. }\end{array}$} \\
\hline \multicolumn{3}{|c|}{ c Product claim and reminder advertisement. } \\
\hline \multicolumn{3}{|c|}{$\begin{array}{l}\text { d Patent for product expired since study's publication, opening up the market to generic equivalents. } \\
\text { e Product also featured in } 2016 \text { sample. }\end{array}$} \\
\hline
\end{tabular}

provided substantially less information about the biologic nature of the conditions, risk factors, and populations at risk. Similarly, there was a decrease in use of negative emotional appeals often associated with the challenges of coping with health issues. Pharmaceutical advertisers may be relying less on fearmongering, a tactic shown to be ineffective in health campaigns. ${ }^{16-19}$ This finding, however, may also indicate an underrepresentation of the full context of patients' lives in relation to their health conditions. More importantly, by further de-emphasizing lifestyle changes, the role of medication in the experience and management of a patient's health is decontextualized. ${ }^{14}$

In discussing the educational shortcomings of DTCA, it is worth noting that while the ads have become longer (by $30 \%$ ), their potential educational value has declined compared with the 2004 sample. This presents a disconnect with PhRMA's guidelines and other proponents of DTCA that set the expectation that the ads promote health and disease awareness above product endorsement. ${ }^{11,12}$ To that point, Frosch et $\mathrm{a}^{120}$ outlined the ways in which the drug industry could improve the usefulness of DTCA for consumers (eg, more precise information on health benefits of drugs drawn from published studies, acknowl-

the reported drug benefits at the expense of information about the health condition. This pattern was identified in the 2004 ads but the gap between educational and promotional content within the advertisements has increased. Specifically, the 2016 ads were more likely to portray only the post-medication experience compared with the 2004 ads, and the post-medication experience was more often depicted with healthy or recreational activities, endurance, social approval, and regaining control as benefits of medication use. Such portrayals may have great motivational and empowering value, be beneficial in destigmatizing conditions, and prove helpful for patient adherence. Nonetheless, such expansive promotion of drug benefits could imply off-label outcomes and encourage an inappropriately broad population to seek the advertised drug. ${ }^{15}$

Concern about ad messages attracting an overly broad audience is exacerbated by the accompanying reduction in health condition information in the ads. Compared with 2004, the current sample of DTCA edgment of generic alternatives available). It is clear these suggestions have not been heeded.

This study had several limitations. Content analysis does not account for advertising effects on audience members. The findings warrant further research testing the efficacy of ad features to educate the public on health conditions and assessing consumers' interpretations of the emotional and psychological benefits found in DTCA.

For consistency with the 2004 sample, our coding scheme did not assess adherence to the fair balance doctrine, the analysis focused on product claim advertising rather than help-seeking ads, and the sampling method relied on prime-time programming. It is possible advertisers have replaced some of the health condition information to allow for more comprehensive risk information disclosure. Given the widening gap between drug promotion and health education evident in the our results, additional research is needed to understand how pharmaceutical advertisers may be using help-seeking 
ads. Lastly, future research should investigate DTCA aired on niche networks and cable channels such as ESPN, Lifetime, or BET to see if differences exist in messages designed for narrower populations.

In conclusion, balancing motivation and adherence goals with the need for evidence-based accuracy and appropriate targeting deserves more attention than ever considering current advertising practices. Given the debate surrounding whether these ads serve to educate or persuade consumers, this study shows that pharmaceutical ads currently provide health education. In response to ongoing scrutiny and proposals to tighten restrictions, PhRMA put forth guiding principles in 2005 and 2008 urging its members to go beyond the basic FDA requirements for advertising prescription drugs. ${ }^{11,12}$ These principles repeatedly call for efforts to educate patients about health conditions and alternative treatment options and to promote only well-substantiated drug claims. In concluding their findings, Frosch et al ${ }^{20}$ were pessimistic that self-regulatory measures would be sufficient and our results suggest that self-regulation has done little to improve the educational quality of DTCA. If these ads are to fulfill a public health function in addition to a drug marketing function, policy makers will likely need to take further regulatory action to codify those expectations.

To read or post commentaries in response to this article, see it online at http://www.AnnFamMed.org/content/16/3/211.

Key words: prescription drug advertising; DTC; direct-to-consumer advertising; DTCA; content analysis; pharmaceutical industry

Submitted August 29, 2017; submitted, revised, November 21, 2017; accepted December 5, 2017.

Funding support: This work was supported, in part, by the University of South Florida Research $\&$ Innovation Internal Awards Program under Grant No. 0115756.

Acknowledgments: The authors are grateful for the University of South Florida's Office of Research and Innovation, which funded a grant that made this data collection possible. We are also thankful to Danielle Quichocho, Sarah Chesser, Dena Van Lengen, Sara Sturgess, and Matthew Giardino for their involvement in the coding process.

\section{References}

1. Celia F. Pharma ups the ante on DTCA. Pharmaceutical Commerce. http://pharmaceuticalcommerce.com/brand-marketingcommunications/pharma-ups-ante-dtc-advertising. Published Apr 4 2017. Accessed Aug 17, 2017.

2. Ball JG, Manika D, Stout P. Consumers young and old: segmenting the target markets for direct-to-consumer prescription drug advertising. Health Mark Q. 2011;28(4):337-353.
3. DiJulio B, Firth J, Brodie M. Kaiser Health tracking poll: October 2015. The Henry J. Kaiser Family Foundation. http://www.kff.org/ health-costs/poll-finding/kaiser-health-tracking-poll-october-2015. Published Oct 28, 2015. Accessed Aug 17, 2017.

4. Mintel Academic. Pharmaceuticals Consumer-US-March 2011. http://academic.mintel.com/display/569299/?__cc=1. Published 2011. Accessed Aug 17, 2017.

5. Frosch DL, Krueger PM, Hornik RC, Cronholm PF, Barg FK. Creating demand for prescription drugs: a content analysis of television direct-to-consumer advertising. Ann Fam Med. 2007;5(1):6-13.

6. Stange KC. Time to ban direct-to-consumer prescription drug marketing. Ann Fam Med. 2007;5(2):101-104.

7. US Food and Drug Administration. The future of drug safety: promoting and protecting the health of the public. https://www. fda.gov/downloads/Drugs/DrugSafety/PostmarketDrugSafety InformationforPatientsandProviders/UCM171627.pdf. Published 2007. Accessed Aug 17, 2017.

8. American Medical Association. AMA calls for ban on DTC ads of prescription drugs and medical devices. https://www.ama-assn.org/ content/ama-calls-ban-direct-consumer-advertising-prescriptiondrugs-and-medical-devices. Published 2015. Accessed Nov 20, 2017.

9. US Food and Drug Administration. Food and Drug Administration Amendments Act of 2007. https://www.fda.gov/Regulatorylnformation/LawsEnforcedbyFDA/SignificantAmendmentstotheFDCAct/Food andDrugAdministrationAmendmentsActof2007/default.htm. Published 2007. Updated Dec 2, 2011. Accessed Nov 20, 2017.

10. US Food and Drug Administration. Advertising. https://www.fda. gov/Drugs/GuidanceComplianceRegulatorylnformation/Guidances/ ucm064956.htm. Published 2016. Updated Oct 2, 2016. Accessed Aug 17, 2017.

11. Royne MB, Myers SD. Recognizing consumer issues in DTC Pharmaceutical Advertising. J Consum Aff. 2008;42(1):60-80.

12. PhRMA guiding principles: Direct to consumer advertisements about prescription medicines. Pharmaceutical Researcher and Manufacturers of America (PhRMA). http://phrma-docs.phrma.org/sites/ default/files/pdf/phrmaguidingprinciplesdec08final.pdf. Published 2008. Accessed Aug 17, 2017.

13. US Food and Drug Administration. U.S. Department of Health and Human Services. https://www.fda.gov/ForConsumers/Consumer Updates/ucm107170.htm. Published 2016. Updated Jun 14, 2016. Accessed Jul 2, 2017.

14. Applequist J. Broadcast Pharmaceutical Advertising in the United States: Primetime Pill Pushers. Lanham, MD: Lexington; 2016.

15. Cline RJW, Young HJ. Direct-to-consumer print ads for drugs: do they undermine the physician-patient relationship? J Fam Pract. 2005;54(12):1049-1057.

16. Lurie P. DTC advertising harms patients and should be tightly regulated. J Law Med Ethics. 2009;37(3):444-450, 396.

17. Ruiter RAC, Abraham C, Kok G. Scary warnings and rational precautions: a review of the psychology of fear appeals. Psychol Health. 2001;16(6):613-630.

18. Rogers RW. A protection motivation theory of fear appeals and attitude change. J Psychol. 1975;91(1):93-114.

19. Witte K, Allen M. A meta-analysis of fear appeals: implications for effective public health campaigns. Health Educ Behav. 2000;27(5): 591-615.

20. Frosch DL, Grande D, Tarn DM, Kravitz RL. A decade of controversy: balancing policy with evidence in the regulation of prescription drug advertising. Am J Public Health. 2010;100(1):24-32. 